Vol. XXV No 2019

\title{
ATTITUDES TO GENDER ROLES IN ROMANIA
}

\author{
Raluca RUSU, Alexandru BABOȘ \\ "Nicolae Balcescu" Land Forces Academy, Sibiu, Romania \\ rbalasoiu@yahoo.com
}

\begin{abstract}
The paper analyses the attitude towards gender roles and their dynamics in Romania in the context of economic, social, political and cultural changes due to the transition from the traditional, modern to the postmodern society. In order to achieve this goal, we used the attitude measurement scale versus the gender roles used in two stages of the World Value Survey 2014, 2018.
\end{abstract}

\section{Keywords: gender roles, attitudes towards gender roles, World Value Survey}

1. Dynamic roles - from traditionalism, modernity and postmodernity

We have certainly gone a long way since a single woman walking alone on the street was considered inappropriate in most countries. Today, women and men share both public and private space together.

Transforming gender roles is part of the wider cultural change from traditional culture to modern and then postmodern culture. Considering that traditional culture patterns value religious authority and belonging to the local community and family, it encourages inequality between women and men, playing different roles in family and society.

Modern society came with the industrialization, urbanization, and the decline of religious authority throughout society, gradually the traditional authority was replaced by rational-legal authority [1]. Industrialization has led to increased workforce needs and, consequently, greater involvement of women on the labour market. Starting from the idea that "the modernization process offers opportunities to develop new values such as personal liberty, self-development, self-expression, creativity, equality and democracy" [2], the values involved in gender relations become more egalitarian. In this context, people are more willing to support changing gender roles, resulting in greater male engagement in domestic work while increasing women's participation in the labour market and women's need for greater self-development and self-expression.

The transition from modern to postmodern society has been marked by multiple economic, social and cultural changes, which has led to the emergence of new value patterns in politics, religion, family and work. Since postmodernism encourages diversity and individual and group differences, the shift from modernity to postmodernity meant changing the way women perceive their own self-realization, which also affected how they began to be represented in society. Namely, the transition from the image of mother and housewife to the image of an independent person involved in the workplace occurred.In conclusion, we can say that at present we are talking about gender equality 
between men and women both in the public and in the private space.

\section{Definition and theoretical framework}

Gender roles are norms of interaction and expectations about the division of labour between men and women. Defined in this way, gender roles depend on the culturalhistorical context in which they appear. The simplest definition of gender roles states the idea that they present a set of expectations about male and female behaviour [3].

As a consequence of adopting new gender roles and especially of the modern way of seeing the role of women in family and society, one can distinguish between traditionalist and egalitarian attitudes towards gender roles. Traditional attitudes to gender roles support the idea that the woman is the one to whom private space belongs, having the role of taking care of the children and the house. While the man works in public space, his role is to provide for the needs of the family. On the other hand, gender attitudes towards gender roles are based on factors that are not genderbased [4].

The increase in women's presence on the labour market and the emergence of feminist ideas have emphasized gender equality in all aspects of social and personal life [5].

Gender equality has two large interrelated dimensions, the first involving equal opportunities for men and women on the labour market, in the educational process and in the political system. This dimension also refers to activities in the private sphere as an equal sharing of household, financial and childcare responsibilities. The second dimension is the subjective part of gender equality in terms of people's attitudes towards these issues. Even if it is subjective, it is equally important because it affects people's decision-making, behaviours and even their well-being.

This work focuses on the subjective dimensions of gender equality, namely the attitudes without them, both in the public and in the private sphere of life. Studying and understanding attitudes to gender roles is relevant for the implications of democratization,fertility, and achievements in the sphere of education, political participation, leadership, and division of labour.

Other authors have conceptualized differently attitudes related to gender roles. Thus, another point of view emphasizes the idea of sameness, a concept by which gender equality is seen as equal opportunities and rights for women and men. Every individual, regardless of gender, should have access to the same rights, opportunities; individuals should be treated according to the same rules and standards [6].

The perspective of difference argues that gender neutrality does nothing but strengthen the dominant masculine perspective, and that differences between men and women should be recognized and valued. And the third point of view is that of the genderas a whole, the prospect that would simulate the previous dichotomy, which only exacerbates and creates inequalities.

The research in this field has focused on two directions, some of which we are trying to emphasize in this paper, on the one hand, identifying attitudes towards gender roles and how they were influenced by the socioeconomic contexts. On the other hand, more recently, research has expanded by trying to explain comparatively and longitudinally the differences between gender values in different societies. The big issue of researchers who have conducted cross-cultural studies was to identify a comparable measurement scale for different cultures and societies. The most used scale is included in one of the most popular international surveys, the World Values Survey.

Attitudes towards gender roles appear in the literature under different labels, and, as a result, they have been defined in various forms. In general, attitudes are seen as 
normative preferences for a certain distribution of roles between men and women, both in the private family environment and in the public sphere of political leadership and in the workplace [7]. These preferences are expressed in beliefs about placing women in political leadership, and men as active participants in household and child care.

\section{Attitudes towards gender roles in Romania}

We will further analyse attitudes towards gender roles starting from the scale included in the last two stages of the World Values Survey (WVS) $(2014,2018)[8]$ in Romania. We will also try to identify differences in attitudes towards gender roles in different societies/cultures.

As you can see in Figure 1, the smallest score has the item:men make better political leaders than women do, namely 22.8 , what shows us that in the public sphere of life, management positions are still seen as belonging to men.

Regarding this item,most respondents which consider that men are better leaders than women, are men, namely $47 \%$ and $34 \%$ arefemales.Also, the itemwhen jobs are scarce, men should have more right to a job than women, has a higher mean, which indicates the same thing, that public sphereis dominated by men. The item's mean (32.6) having a job is the best way for a woman to be an independent personindicates us that women's independence is valued more and more in Romania.

Furthermore, we will focus on how gender attitudes look according to the 2018 wave of World Value Survey, comparativewith the 2014 wave.

As it can be seen in Table 1, the high average is maintainedfor items: men make better business executives than women do andon the whole, men make better political leaders than women do, which shows us that gender attitudes have not changed in Romania from 2014 wave.

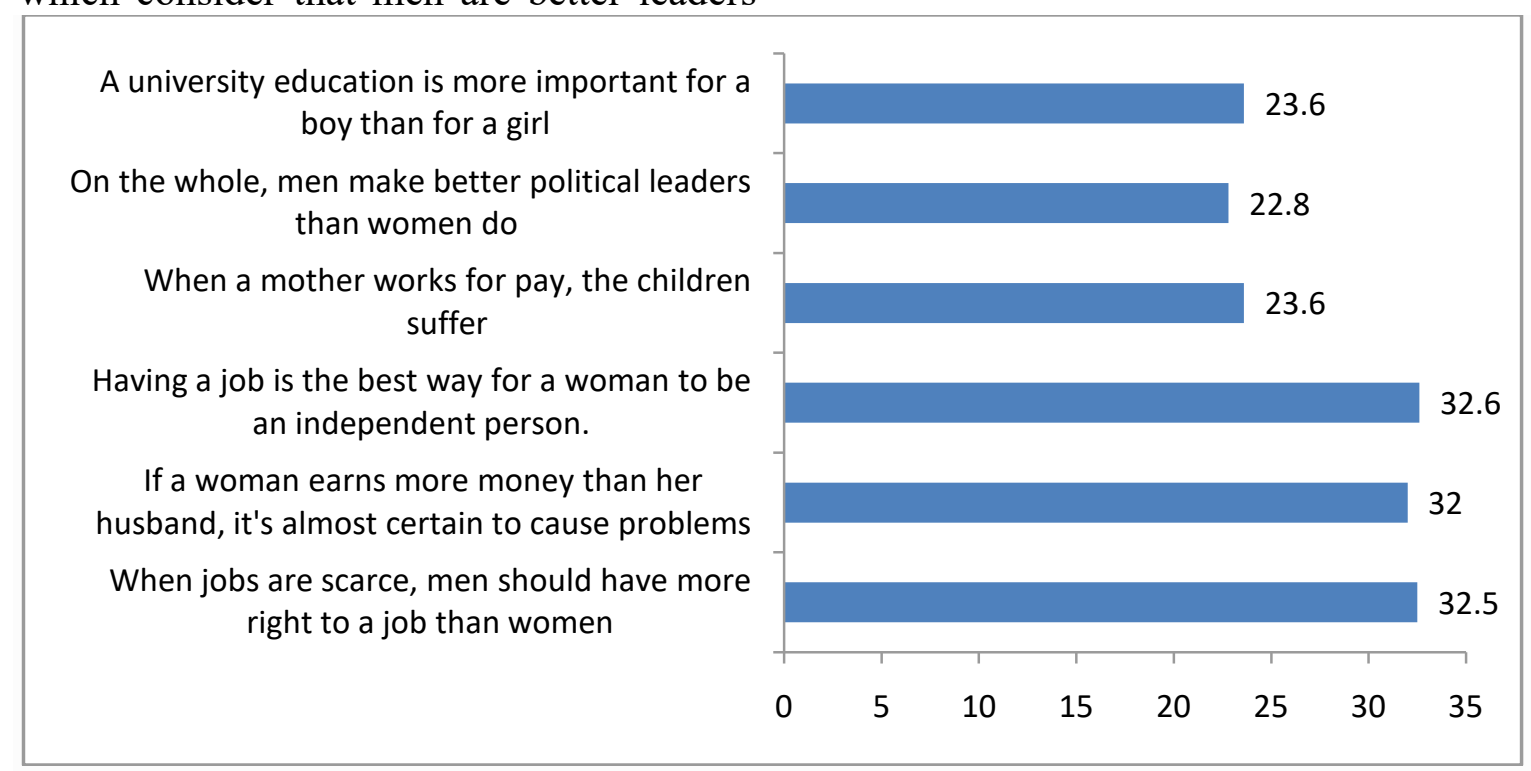

Figure 1: Items included in the attitude measurement scale ofgender roles from WVS 2014(means) 
Table 1 Descriptive statistics for the items measuring attitudes towards gender roles in WVS 2018

\begin{tabular}{|l|l|l|l|l|}
\hline & Min & Max & Mean & Std.Dev \\
\hline Family life suffers when the woman works full-time & 1 & 4 & 2.88 & 1.34 \\
\hline $\begin{array}{l}\text { A man's job is to earn money, a woman' job is to care for } \\
\text { children }\end{array}$ & 1 & 4 & 2.66 & 1.27 \\
\hline $\begin{array}{l}\text { When jobs are scarce, men should have more rights to a } \\
\text { job than women }\end{array}$ & 1 & 4 & 3.01 & 1.61 \\
\hline $\begin{array}{l}\text { On the whole, men make better political leaders than } \\
\text { women do }\end{array}$ & 1 & 4 & 3.11 & 01.67 \\
\hline $\begin{array}{l}\text { A university education is more important for a boy than } \\
\text { for a girl }\end{array}$ & 1 & 4 & 3.49 & 1.45 \\
\hline $\begin{array}{l}\text { On the whole, men make better business executives than } \\
\text { women do }\end{array}$ & 1 & 4 & 3.77 & 1.57 \\
\hline
\end{tabular}

The research revealsthat gender attitudesdo not varyaccording to socio demographic variables: sex, marital status, age, and education level.

Regardingthe item that refers to the extent to which men are involved in the housework, in a cross-cultural analysis, we can notice that there is less inequality in Romania than in other countries, which means that there issome gender equality in the private sphere of life, at least. (figure 2)

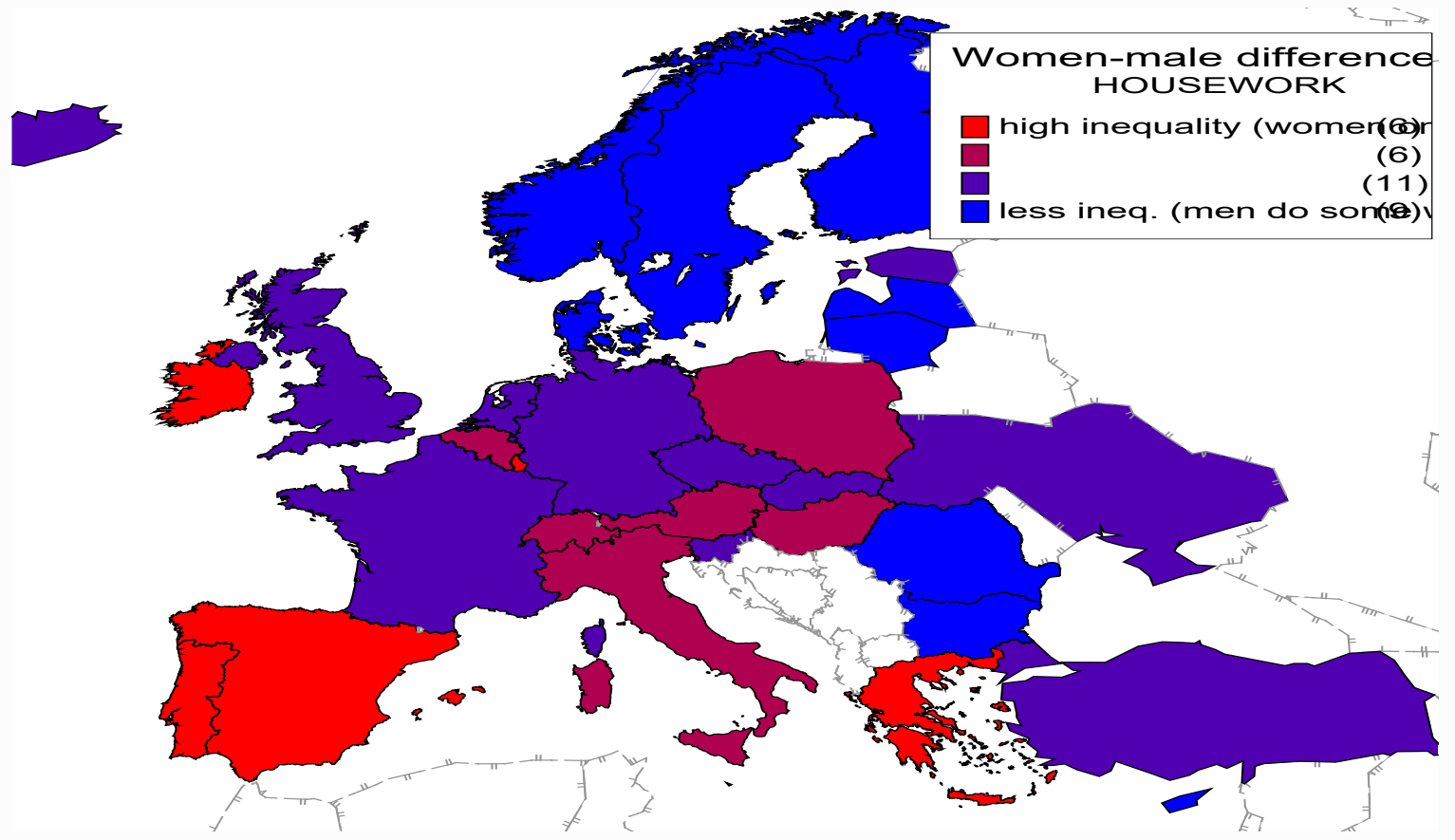

Figure 2 Women-male difference in doing housework

\section{Conclusions}

Attitude to gender roles is a complex and multidimensional concept,including at least two dimensions:balance of power from men and women (inequality or equality) and the space in which these roles are manifested(private-public). The scale used 
by WVS has a traditionalist orientation, with questions aboutonly traditionalist and specialized attitudes to gender roles.

Agreeing with these items shows a strong traditionalist orientation on gender roles in the public sphere, but disagreement with them does not necessarily suggest egalitarianism in gender roles.

\section{References}

[1] Max Weber Economie si societate, Ed. Politica, 1972.

[2] Easter, Peter, Halman, Loek, de Moor, Ruud (1993) - 'Values Shift in Western Societies' in Easter Peter, Loek Halman, Ruud de Moor (eds.) - The Individualizing Society: Values Change in Europe and North America, Tilburg University Press, Tilburg, pp. 1-21Authors, Journal of Manufacturing Systems, Vol. 15, No. 6, 1996. pp. 432-442.

[3] Myres, D. G. (2010). Social psychology. New York: McGraw-Hill.

[4] Vuksan, G. (2009). [Attitudes of Adolescents about Gender Roles and Perceived Attitudes of their Parents.MA thesis. Zagreb: Department of Psychology, Faculty of Humanities and Social Sciences.

[5] Inglehart, R., Norris, P., \&Welzel, C. (2002). Gender equality and democracy.Comparative Sociology, 1(3-4), 321-345.

[6] Walby, Sylvia (2005). "Gender Mainstreaming: Productive Tensions un Theory and Practice, Social Politics 12: 321-343.

[7] Kane, E. W. (2000). Racial and ethnic variations in gender-related attitudes. Annual Review of Sociology, 26, 419-39.

[8] Inglehart, R.,C., Haerpfer, A. Moreno,C.Welzel,K.Kizilova, J. Diez-Medrano, M.Lagos, P. Norris, E. Ponarin and B. Puranen et al. (eds.). 2014 World Value Survey:Round SixCountry -Pooled. Version:

http://www.worldvaluessurvey.org/WVSDocumentationWV6.jsp. 